\title{
Effect of Household Wastes on Individuals Health in Rural Villages at Assiut Governorate
}

\author{
Shimaa Abd El-Rady Abd-Elaa, Farag Mohammed Moftah, Soad Sayed Bayomi \& Amira Abdallah \\ El-Houfey
}

Nursing Specialist at El-Ghanayem Hospital in Assiut Governorate.

Professor of Public Health and Community Medicine, Faculty of Medicine, Assiut University.

Assistant Professor of Community Health Nursing, Faculty of Nursing, Assiut University.

Lectuer of Community Health Nursing, Faculty of Nursing, Assiut University

\begin{abstract}
Background: Improper disposal of household wastes cause health problem to the people from this problem irritation in eye, gastrointestinal problem, headache and allergies...etc. Aim of study: evaluate effect of household wastes on individuals health in rural villages at Assiut Governorate through assessing participant's knowledge, attitude and behavior about household waste disposal. Subjects and Method: Study conducted in Elwaan and Elmashiaa villages at Assiut Governorate. Descriptive research was used in the study. Tools composed of, first part socio-economic scale, second part knowledge questionnaire about waste disposal, third part attitude rating scale about waste disposal, fourth part behaviors questionnaire about waste disposal and fifth part effect of wastes on health. Results: findings of the study revealed that diarrhea and eye diseases are the most common disease caused by wastes followed by skin diseases, parasitic disease, dysentery, typhoid fever, scorpion bites, poisoning, hepatitis A virus (HAV) and snakes bites. It was clear that (61.2\%) of participants had poor behavior. Conclusion: there were relation between poor wastes disposal and diseases and relation between caring with animals and birds in the house and diseases. Recommendations: health education program to the public about solid waste and its related issues through mass media.
\end{abstract}

\section{Key words: Household wastes, Knowledge, Attitude, Behaviors \& Effect.}

\section{Introduction}

Household waste is a movable solid item arising from human activities, that is discarded as useless or unwanted and derived from house and that has no value (Fischer and Crowe, 2000).

Household solid wastes consists of waste food, vegetable peelings and other organic matter. Other components of household solid waste include plastics, paper, glass, textiles, cellophane, metals and some hazardous waste from household products such as paint, garden pesticides, pharmaceuticals, fluorescent tubes, personal care products, batteries containing heavy metals and discarded wood treated with dangerous substances such as anti-fungal and anti-termite chemicals. Also, from wastes found in rural areas animal, bird and agricultural wastes (Fischer and Crowe, 2000).

Household waste cause breeding of insects and rodents living in their environment. The most common vectors are mosquitoes, flies, ticks, roaches, fleas, rats, mice, ground squirrels, snakes and scorpion. All of these agents can serve as reservoirs for germs that they then transmit through physical contact with humans or by contaminating human food stuffs or water (Allender et al., 2010).

Improper disposal of household products can cause a lot of health problem to the people such as irritation in nose and eye, gastrointestinal problem, E.g. (diarrhea, dysentery), fatigue, headache, psychological problem and allergies. Over crowded housing may exacerbate problems in managing human waste, which may taint food stuffs and contribute to the spread of communicable disease (Nies and McEwen, 2012).

The primary responsibilities of the Community Health Nurse (CHN) are advocacy and education of the client in the home, at work and in the community. Primary prevention is to focus of the educating people about safe solid wastes disposal methods. Nurse make intervention to help in minimizing the potential for illness transmission from insect and rodents that can come in contact with infectious agents and spread disease (Smith and Maurer, 2000).

Secondary prevention, strategies are aimed at early diagnosis, early treatment interventions and attempts to limit disability through assess homes for environmental hazards. Preventive activities are aimed at early disease detection thereby increasing opportunities for interventions to prevent progression of the diseases and emergency of symptoms (Nies \& McEwen, 2012).

Tertiary prevention, $\mathrm{CHN}$ are encourage clean up of toxic waste sites and removable of waste hazards. Provide appropriate nursing care at home or work 
sites for persons with chronic disease and injury. Reduces the negative impact of an already established disease by restoring function and reducing disease related complications e.g. rehabilitative measures (Keller et al., 2004).

\section{Aim of the Study}

Identify the effect of household wastes on individual's health in rural villages in Assiut Governorate through assessing the knowledge, attitude and behavior of the studied sample regarding household wastes and its impact on individuals health.

\section{Research questions}

1.Is there relation between sex and knowledge about household wastes?

2. Is there relation between behavior of participants and diseases caused by household wastes?

3 . Is there relation between caring with animals in the house and diseases caused by household wastes?

\section{Subjects and Methods Research design}

The descriptive research was used in this study.

\section{Settings:}

Two villages one in the north (Elwaan) which located at Assiut district and one in the south (Elmashiaa) which located at El-Ghanayem district used in this study.

\section{Sample:}

Two villages were chosen randomly from total number of villages (15), the total number of homes in Elwaan were (1300) home and Elmashiaa were (1850). A systematic random sampling technique was used for selecting the study homes. The sample was including parents (father or mother) in the selected houses. Sample size was 5\% from the total number of population. The total number of population in the two villages was (29010) individuals so, the total sample size was (1450) individuals, (590) individuals from Elwaan village and (860) individuals from Elmashiaa.

\section{Tools of the study:}

One tool used for collecting data it include:

Part (1) Socio-economic: it composed of questions related to socio-demographic and economic characteristics of the participant such as (name, age, sex, education, occupation, monthly income and number of people in the house...etc). The scoring system were $<50 \%$ were low socio economic level, $50 \%$ to $<75 \%$ were middle socio economic level and $>75 \%$ were high socio economic level. (Abd El tawab, 2004).
Part (II): It included questions related to participant's knowledge about safe household solid waste disposal such as (the improper household waste disposal harmful, the participants knowledge about the diseases that may be caused by household wastes such as diarrhea, cholera, dysentery ...etc). The scoring system were $<50 \%$ were poor knowledge, $50 \%$ to $<75 \%$ were satisfactory knowledge and $>75 \%$ were good knowledge.

(Okechukwu et al., 2012).

Part (III): Attitude rating Scale:

A likert scale was used to assess participant's attitude regarding household waste disposal the answer of the question classified into (strongly agree, agree, uncertain, disagree and strongly disagree). The scoring system were $<60 \%$ were negative attitude and $>60 \%$ were positive attitude. (Naing, 2009). Part (IV) : Behavior questionnaire:

It included questions related to participant's behaviors about safe household solid waste disposal such as (who collect household waste, wear gloves during collecting the household wastes...etc and also contain types of household wastes and methods of waste disposal and also, contain if the participant caring with animal and bird in the house. The scoring system were $<50 \%$ were poor behavior, $50 \%$ to $<75 \%$ were satisfactory behavior and $>75 \%$ were good behavior. (Naing, 2009).

Part (V): Effect of household wastes on the health:

It included questions related to effect of household waste on the health of the individual e.g. (diarrhea, dysentery, typhoid fever, HAV, poisoning...etc) which occurred to the family members in the last six months (Ladu et al., 2012).

\section{Field work}

1. An approval letter was taken from Dean of Faculty of Nursing to Directorate of Health Affairs at Assiut to conduct the study and this letter was presented to the director of the health center at Elmashiaa and another copy was presented to the director of the health center at Elwaan to enter the villages and collect the data.

2. Data was collected in the period from $15^{\text {th }}$ of April 2013 until $30^{\text {th }}$ of June 2013. The researcher introduced herself to the director of the health centers at Elmashiaa and to the director of the health centers at Elwaan and presented to them a copy of letter was taken from Directorate of Health Affaires at Assiut Governorate. The researcher introduced herself to the household head and explained to him the nature and the purpose of the study then a complete confidentiality of data was assured. After that the researcher begins to address 
the participant questions to fill the questionnaire sheet.

3. The researcher trained two social workers to collect the data from Elwaan village and communicates with the assistants if any problem or difficultly faced them while collecting data.

\section{Ethical consideration}

At the initial interview, each participant was informed of the purpose and the nature of the study and the researcher emphasized that the participation would be voluntary; hence every participant had the right to participate or refuse to be included in the study. The consent for participation was taken orally. In addition, the confidentiality of the data was maintained and explained.

\section{Pilot study}

Pilot study was carried out before the beginning of the data collection on (40) participants. The aim of the pilot study is to test the clarity of the tool and to estimate the required time to fill the questionnaire. Based on the result of the pilot study the necessary modification in the tool was done. The pilot study sheet was excluded from the whole study. Statistical analysis

Collected data were coded and verified prior to data entry. The entered data were revised before conducting the statistical analysis. Descriptive statistics (i.e., frequencies, percentage, mean and standard deviation, etc...) were calculated using (Statistical Package for Social Science) SPSS PC version 20 .

\section{Results}

Table (1): Distribution of the studied sample regarding their socio- demographic characteristics at EImashiaa \& Elwaan villages, 2013

\begin{tabular}{|c|c|c|}
\hline Socio-demographic characteristics & No. $(n=1450)$ & $\%$ \\
\hline \multicolumn{3}{|l|}{ Villages: } \\
\hline Elmashiaa & 860 & 59.3 \\
\hline Elwaan & 590 & 40.7 \\
\hline \multicolumn{3}{|l|}{ Age: } \\
\hline 19 - year & 405 & 27.9 \\
\hline 33 - year & 784 & 54.1 \\
\hline 47 - year & 235 & 16.2 \\
\hline$\geq 61$ year & 26 & 1.8 \\
\hline Mean \pm SD & \multicolumn{2}{|c|}{$38.5 \pm 9.3$} \\
\hline \multicolumn{3}{|l|}{ Gender: } \\
\hline Male & 791 & 54.6 \\
\hline Female & 659 & 45.4 \\
\hline \multicolumn{3}{|l|}{ Marital status: } \\
\hline Married & 1420 & 97.9 \\
\hline Widow & 21 & 1.5 \\
\hline Divorce & 9 & 0.6 \\
\hline
\end{tabular}

According to research question nol. Is there relation between sex and knowledge about household wastes?

Table (2): Relations between sex and knowledge about safe household waste disposal at Elmashiaa \& Elwaan villages, 2013

\begin{tabular}{|c|c|c|c|c|c|c|c|}
\hline \multirow{3}{*}{ Variables } & \multicolumn{6}{|c|}{ Knowledge level about waste disposal } & \multirow[t]{3}{*}{ P. Value } \\
\hline & \multicolumn{2}{|c|}{$\begin{array}{c}\text { Male participant } \\
(\text { No.= }=791)\end{array}$} & \multicolumn{2}{|c|}{$\begin{array}{c}\text { Female participant } \\
(\text { No.= 659) }\end{array}$} & \multicolumn{2}{|c|}{$\begin{array}{c}\text { Total } \\
(\text { No= 1450) }\end{array}$} & \\
\hline & No. & $\%$ & No. & $\%$ & No. & $\%$ & \\
\hline Poor knowledge & 64 & 8.1 & 102 & 15.5 & 166 & 11.4 & \multirow{4}{*}{$0.002 *$} \\
\hline Satisfactory knowledge & 349 & 44.1 & 276 & 41.9 & 625 & 43.1 & \\
\hline Good knowledge & 378 & 47.8 & 281 & 42.6 & 659 & 45.5 & \\
\hline Total & 791 & 100.0 & 659 & 100.0 & 1450 & 100.0 & \\
\hline
\end{tabular}


Table (3): Relations between socio-economic level of the studied sample \& diseases caused by waste, 2013

\begin{tabular}{|c|c|c|c|c|c|c|c|c|c|}
\hline \multirow{3}{*}{ \# Variable } & \multicolumn{8}{|c|}{ Socio-economic Level } & \multirow{3}{*}{ P. value } \\
\hline & \multicolumn{2}{|c|}{ Low $=305$} & \multicolumn{2}{|c|}{ Moderate $=808$} & \multicolumn{2}{|c|}{ High =337 } & \multicolumn{2}{|c|}{ Total $=1450$} & \\
\hline & No. & $\%$ & No. & $\%$ & No. & $\%$ & No. & $\%$ & \\
\hline Diarrhea & 213 & 69.8 & 545 & 67.5 & 218 & 64.7 & 976 & 67.3 & 0.378 \\
\hline Dysentery & 139 & 45.6 & 262 & 32.4 & 62 & 18.4 & 463 & 31.9 & $0.001 *$ \\
\hline Eye diseases & 234 & 76.7 & 517 & 64.0 & 218 & 64.7 & 969 & 66.8 & $0.014 *$ \\
\hline Skin diseases & 184 & 60.3 & 430 & 53.2 & 149 & 44.2 & 763 & 52.6 & $0.011 *$ \\
\hline HAV & 79 & 25.9 & 157 & 19.4 & 13 & 3.9 & 249 & 17.2 & $0.001 *$ \\
\hline Typhoid fever & 113 & 37.0 & 252 & 31.2 & 49 & 14.5 & 414 & 28.6 & $0.004 *$ \\
\hline Parasitic disease & 162 & 53.1 & 443 & 54.8 & 102 & 30.3 & 707 & 48.8 & $0.003 *$ \\
\hline Scorpion bites & 118 & 38.7 & 195 & 24.1 & 34 & 10.1 & 347 & 23.9 & $0.013 *$ \\
\hline Snakes bites & 18 & 5.9 & 26 & 3.2 & 3 & 0.9 & 47 & 3.2 & $0.002 *$ \\
\hline $\begin{array}{l}\text { Poisoning from polluted } \\
\text { foods or drinks }\end{array}$ & 81 & 26.6 & 193 & 23.9 & 45 & 13.4 & 319 & 22.0 & $0.005^{*}$ \\
\hline
\end{tabular}

* Statistical significant difference $(P<0.05)$.

Chi-square test

"\#" Mutual answer.

Table (4): Relation between the studied sample's knowledge about safe household wastes disposal \& diseases caused by waste, 2013

\begin{tabular}{|c|c|c|c|c|c|c|c|c|c|}
\hline \multirow{3}{*}{ \# Variables } & \multicolumn{8}{|c|}{ Knowledge Level } & \multirow{3}{*}{ P. value } \\
\hline & \multicolumn{2}{|c|}{ Poor $=166$} & \multicolumn{2}{|c|}{ Satisfactory $=625$} & \multicolumn{2}{|c|}{ Good $=659$} & \multicolumn{2}{|c|}{ Total $=1450$} & \\
\hline & No. & $\%$ & No. & $\%$ & No. & $\%$ & No. & $\%$ & \\
\hline Diarrhea & 111 & 66.9 & 424 & 67.8 & 441 & 66.9 & 976 & 67.3 & 0.932 \\
\hline Dysentery & 61 & 36.7 & 237 & 37.9 & 165 & 25.0 & 463 & 31.9 & $0.001^{*}$ \\
\hline Eye diseases & 105 & 63.3 & 438 & 70.1 & 426 & 64.6 & 969 & 66.8 & 0.069 \\
\hline Skin diseases & 80 & 48.2 & 355 & 56.8 & 328 & 49.8 & 763 & 52.6 & $0.020^{*}$ \\
\hline HAV & 41 & 24.7 & 136 & 21.8 & 72 & 10.9 & 249 & 17.2 & $0.003^{*}$ \\
\hline Typhoid fever & 66 & 39.8 & 207 & 33.1 & 141 & 21.4 & 414 & 28.6 & $0.011 *$ \\
\hline Parasitic disease & 77 & 46.4 & 347 & 55.5 & 283 & 42.9 & 707 & 48.8 & $0.021 *$ \\
\hline Scorpion bites & 60 & 36.1 & 177 & 28.3 & 110 & 16.7 & 347 & 23.9 & $0.005^{*}$ \\
\hline Snakes bites & 6 & 3.6 & 29 & 4.6 & 12 & 1.8 & 47 & 3.2 & $0.016^{*}$ \\
\hline $\begin{array}{l}\text { Poisoning from polluted } \\
\text { foods or drinks }\end{array}$ & 48 & 28.9 & 151 & 24.2 & 120 & 18.2 & 319 & 22.0 & $0.003^{*}$ \\
\hline
\end{tabular}

* Statistical significant difference $(P<0.05)$. 
Table (5): Distribution of the studied sample's behaviors about safe household wastes disposal in relation to diseases caused by waste, 2013

\begin{tabular}{|c|c|c|c|c|c|c|c|}
\hline \multirow{3}{*}{ \# Variables } & \multicolumn{6}{|c|}{ Behaviors Level } & \multirow{3}{*}{ P. value } \\
\hline & \multicolumn{2}{|c|}{ Poor $=887$} & \multicolumn{2}{|c|}{ Satisfactory $=563$} & \multicolumn{2}{|c|}{ Total $=1450$} & \\
\hline & No. & $\%$ & No. & $\%$ & No. & $\%$ & \\
\hline Diarrhea & 601 & 68 & 375 & 66.6 & 976 & 67.3 & 0.345 \\
\hline Dysentery & 264 & 30 & 199 & 35.3 & 463 & 31.9 & $0.015^{*}$ \\
\hline Eye diseases & 597 & 67 & 372 & 66.1 & 969 & 66.8 & 0.344 \\
\hline Skin diseases & 450 & 51 & 313 & 55.6 & 763 & 52.6 & $0.040 *$ \\
\hline HAV & 151 & 17 & 98 & 17.4 & 249 & 17.2 & 0.452 \\
\hline Typhoid fever & 237 & 27 & 177 & 31.4 & 414 & 28.6 & $0.001^{*}$ \\
\hline Parasitic disease & 399 & 45 & 308 & 54.7 & 707 & 48.8 & $0.001 *$ \\
\hline Scorpion bites & 181 & 20 & 166 & 29.5 & 347 & 23.9 & $0.015 *$ \\
\hline Snakes bites & 21 & 2 & 26 & 4.6 & 47 & 3.2 & $0.030 *$ \\
\hline $\begin{array}{l}\text { Poisoning from polluted food } \\
\text { or drink }\end{array}$ & 193 & 22 & 126 & 22.4 & 319 & 22.0 & 0.415 \\
\hline
\end{tabular}

* Statistical significant difference $(P<0.05)$.

Chi-square test

"\#" Mutual answer.

Table (6): Relations between diseases caused by waste \& caring with animals in the house, 2013

\begin{tabular}{|l|c|c|c|c|c|}
\hline \multirow{2}{*}{ \# Variables } & \multicolumn{2}{|c|}{ Caring with the animal and bird in the house } & \multirow{2}{*}{ P. value } \\
\cline { 2 - 6 } & \multicolumn{2}{|c|}{ Yes $\mathbf{7 4 0}$} & \multicolumn{2}{c|}{ No= 710 } & \\
\cline { 2 - 6 } & No. & \% & No. & $\%$ & \\
\hline \multicolumn{1}{|c|}{ Diarrhea } & 516 & 69.7 & 460 & 64.8 & $0.026^{*}$ \\
\hline Dysentery & 307 & 41.5 & 156 & 22.0 & $0.001^{*}$ \\
\hline Eye diseases & 501 & 67.7 & 468 & 65.9 & 0.252 \\
\hline Skin diseases & 426 & 57.6 & 337 & 47.5 & $0.001^{*}$ \\
\hline HAV & 171 & 23.1 & 78 & 11.0 & $0.003^{*}$ \\
\hline Typhoid fever & 237 & 32.0 & 177 & 24.9 & $0.002^{*}$ \\
\hline Parasitic disease & 416 & 56.2 & 291 & 41.0 & $0.011^{*}$ \\
\hline Scorpion bites & 248 & 33.5 & 99 & 13.9 & $0.005^{*}$ \\
\hline Snakes bites & 31 & 4.2 & 16 & 2.3 & $0.026^{*}$ \\
\hline Poisoning from polluted foods or drinks & 173 & 23.4 & 146 & 20.6 & 0.109 \\
\hline
\end{tabular}

* Statistical significant difference $(P<0.05)$.

Chi-square test

"\#" Mutual answer.

Figure (1): Distribution of the studied sample regarding socio-economic level at EImashiaa and Elwaan villages, 2013

Socio-economic level

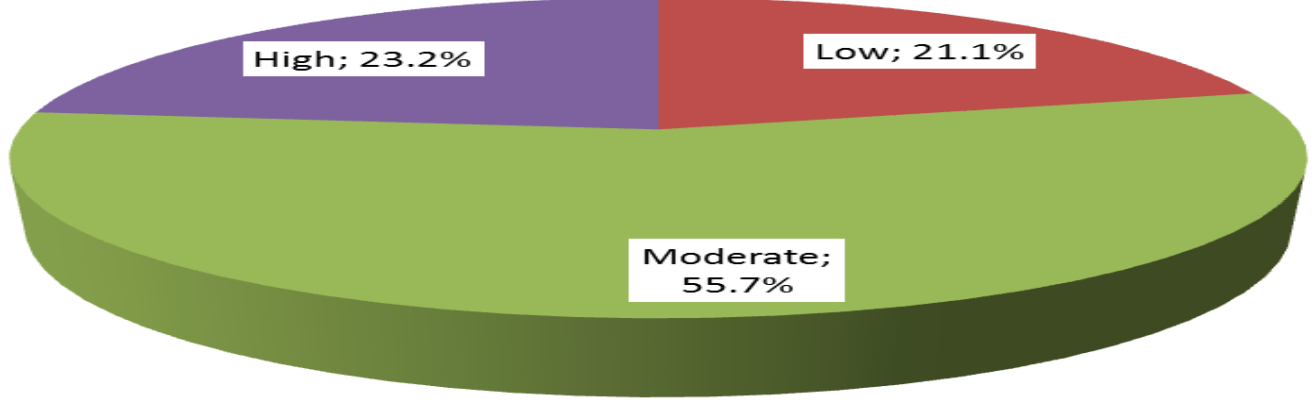


Figure (2): Distribution of the studied sample regarding their knowledge about the safe household waste disposal, 2013

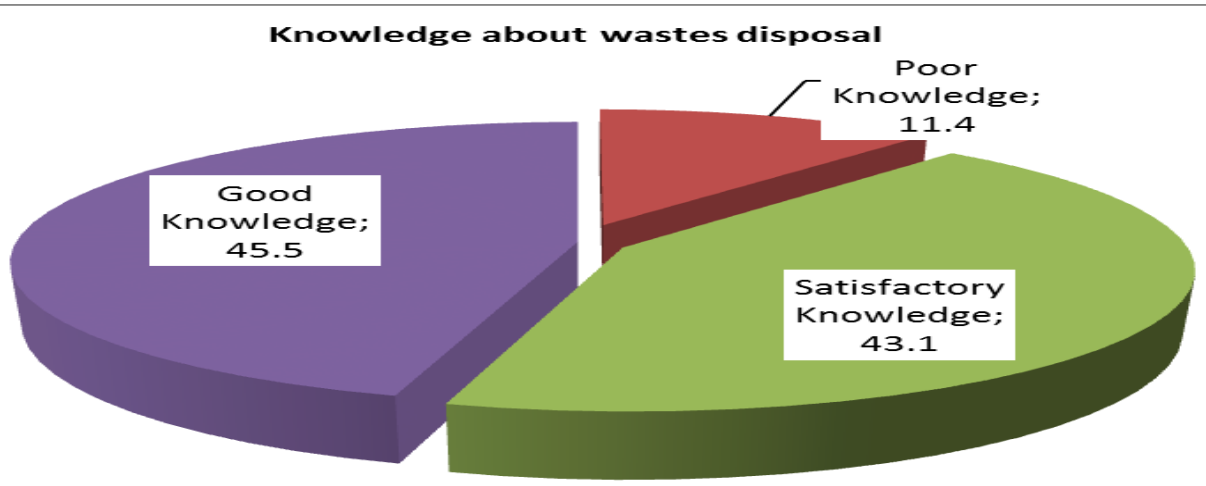

Figure (3): Distribution of the studied sample's attitude regarding household waste management, 2013

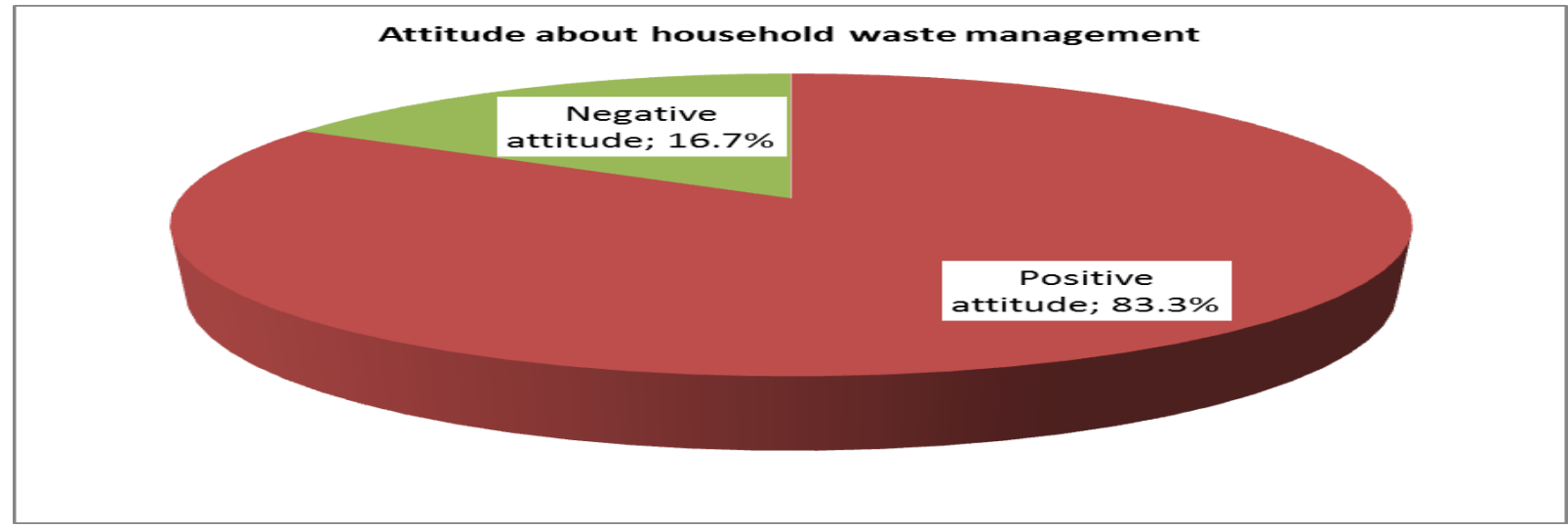

Figure (4): Distribution of the studied sample regarding their behaviors about safe household waste disposal, 2013

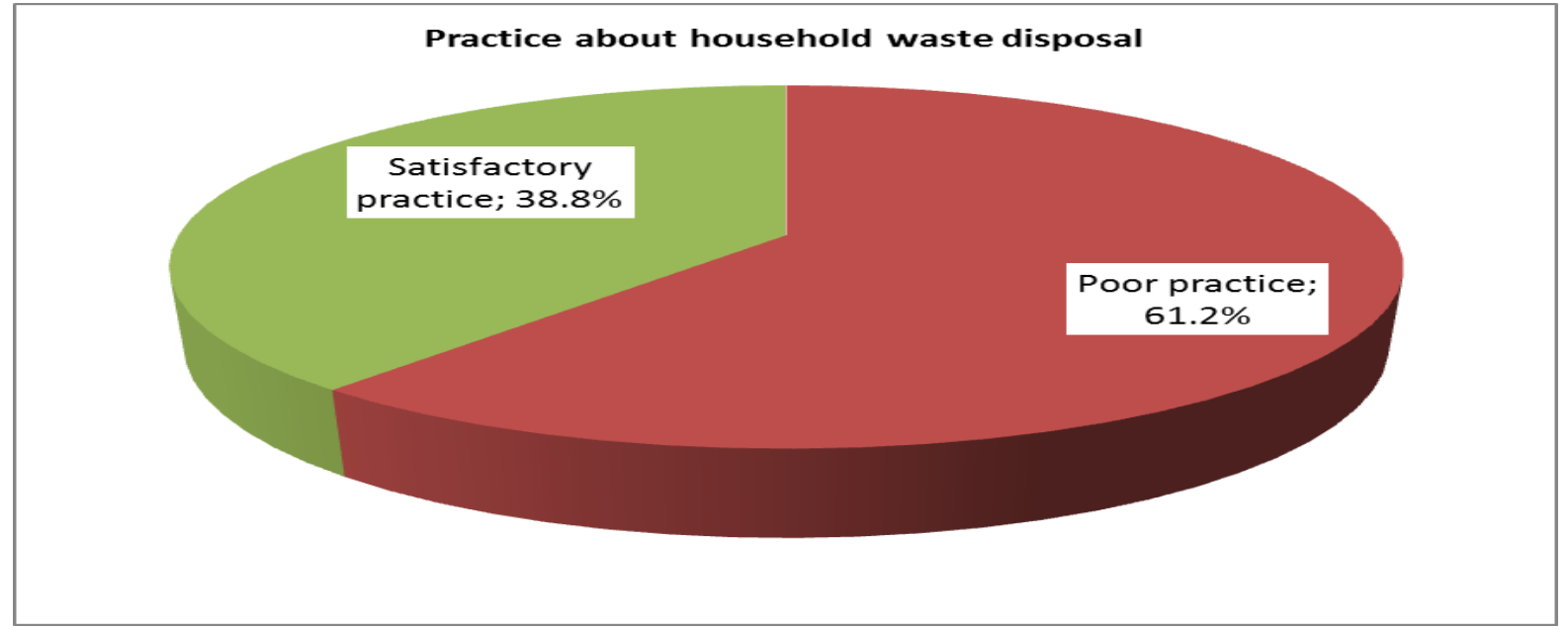


Table (1) \& figure (1): shows the sociodemographic characteristics of the studied sample. It was found that more than half of the studied sample (59.3\%) from Elmashiaa village. The mean age was (38.5) years. Regarding gender more than half $(54.6 \%)$ of the studied sample were males. As regard to the marital status, the vast majority $(97.7 \%)$ of them were married. It was found that $(21.1 \%, 55.7 \%$ $\& 23.2 \%$ ) respectively had low, moderate and high socio-economic level.

Table (2): shows the relation between sex and knowledge about safe household waste disposal, it was found that $(47.8 \% \& 42.6 \%)$ respectively of male and female participants had good level of knowledge about safe household waste disposal while $(44.1 \%$ \& $41.9 \%)$ of male and female participants had satisfactory level of knowledge. But $(8.1 \%$ \& $15.5 \%)$ of male and female participants had poor level of knowledge. All these differences indicate a statistical significant differences between level of knowledge and sex at $\mathrm{P}<0.001$.

Table (3): shows the relation between socioeconomic level of the studied sample and diseases caused by waste, found that diarrhea is the most common disease caused by waste with $67.3 \%$, followed by eye diseases with $66.8 \%$, skin diseases with $52.6 \%$, parasitic diseases with $48.8 \%$, dysentery with $31.9 \%$, typhoid fever with $28.8 \%$, scorpion bites with $23.9 \%$, poisoning from polluted foods or drinks with $22 \%$, HAV with $17.2 \%$ and snakes bites with $3.2 \%$. There is a statistical significant difference with socio-economic levels of the family with all diseases caused by wastes except diarrheal diseases.

Table (4): illustrate relation between the participant's knowledge about household wastes disposal and diseases caused by wastes, found that diarrhea is the most common disease caused by waste with $67.3 \%$, followed by eye diseases with $66.8 \%$, skin diseases with $52.6 \%$, parasitic diseases with $48.8 \%$, dysentery with $31.9 \%$, typhoid fever with $28.8 \%$, scorpion bites with $23.9 \%$, poisoning from polluted foods or drinks with $22 \%$, HAV with $17.2 \%$ and snakes bites with $3.2 \%$. It was found that a statistically significant difference between knowledge level and all diseases caused by wastes except diarrhea and eye diseases.

Table (5): demonstrate distribution of the participant's behaviors about safe household wastes disposal in relation to diseases caused by wastes, found that when comparing the diseases caused by waste with the behaviors level of the participants there was a statistical significant difference in all diseases except diarrhea, eye diseases, HAV and poisoning from polluted food or drinks at $\mathrm{p}<0.05$.

Table (6): shows the relation between diseases caused by waste and caring with animals and birds in the house, it was found that eye diseases and poisoning from polluted foods or drinks hadn't relationship with caring with animals and birds in the house. On the other hand diarrhea, dysentery, skin diseases, HAV, typhoid fever, parasitic diseases, scorpion bites and snakes bites had relation with caring with animals and birds in the house.

Figure (2): illustrate distribution of the participants regarding their knowledge about safe household waste disposal, found that only less than half $(45.5 \%)$ of studied sample had good level of knowledge while $43.1 \%$ had satisfactory level and $11.4 \%$ had poor level of knowledge about safe household waste disposal.

Figure (3): demonstrate the attitude of participants regarding household wastes management, it was found that the majority $(83.3 \%)$ of the studied sample had positive attitude and only $16.7 \%$ had negative attitude.

Figure (4): demonstrate participant's behaviors about safe household wastes disposal, it was found that about three fifths $(61.2 \%)$ of the studied sample had poor behaviors and about $38.8 \%$ of the sample had satisfactory behaviors.

\section{Discussion}

The findings of the present study showed that the mean age of the sample was 38.5 years, Also, in the present study more than half $(54.6 \%)$ of the sample were males and $45.4 \%$ were females. In addition, the great majority of the sample size (97.9\%) was married and only $(0.6 \%)$ was divorced. More than half $(55.7 \%)$ of the study sample had moderate level of socio-economic and about one fifth $(21.1 \%)$ of the study sample had low socio-economic level

The findings of the present study are consistent with study had been carried out by Naing (2009) about factors influencing the practice of household waste management in Ranong, who found that the mean age of the participant are 32.56 years. Another study carried out by Longe et al (2009) about people's perception on household solid waste management in Nigeria, agree with the result of the present study who found that age of the studied sample ranges from $15-70$ years. Similar findings were reported by Abul (2010) who carried out his study about environmental and health impact of solid waste disposal at management dumpsite in Manzini: Swaziland found that $(53.2 \%)$ of participant are males and $(46.8 \%)$ are females.

The findings of this study are disagree with study carried out by Naing (2009) found that $(92.5 \%)$ of sample were females and only $(7.5 \%)$ were males, $(74.8 \%)$ were married and $(5.2 \%)$ were divorced and 
$(55.2 \%)$ of females were housewives. The results of the present study were inconsistence with the results of study carried out by Longe et al (2009) who found that $(62 \%)$ of the sample were males and $(38 \%)$ were females. Approximately $(44 \%)$ of the study sample had moderate socio-economic level and (39\%) of the study sample had low socio-economic level.

The findings of present study indicated that less than half $(45.5 \%)$ of the studied sample had good level of knowledge, $(43.1 \%)$ of the sample had satisfactory knowledge and only (11.4\%) of the sample had poor knowledge. Also, in the present study there were relation between knowledge level about safe household wastes disposal and sex there was a statistical significant difference at table (2).

The findings of current study agree with study carried out by Naing (2009) who conducted his study at Myanmar migrant, found that $(49.8 \%)$ of the sample had good level of knowledge, $(36 \%)$ of the sample had satisfactory knowledge and (14.2\%) of the sample had poor knowledge and the result of present study in the same line with the result reported by Moghadam and Ehrampoush (2005) they found a significant statistical differences between sex of the participants and knowledge regarding wastes disposal at . value $=0.002$.

However the results of current study are partially disagreed with study carried out by Moghadam and Ehrampoush (2005) about knowledge, attitude and practice of Yazd university of medical sciences student about solid wastes disposal and recycling, found that $(15.3 \%)$ of the participants had good knowledge, about $(40.2 \%)$ of the participants had satisfactory knowledge and about $(44.5 \%)$ of the participants had poor knowledge.

In the present study, the majority $(83.3 \%)$ of studied sample had positive attitude and only $(16.7 \%)$ of the studied sample had negative attitude about household waste disposal.

However; these findings are inconsistence with thesis reported by Naing (2009) who conducted their study at Ranong province, found that $(61.2 \%)$ of the sample had fair level of attitude, (36.2\%) of the sample had good level of attitude and $(2.5 \%)$ of the sample had poor level of attitude.

In the current study found that, about three fifths $(61.2 \%)$ of the studied sample had poor level of behavior and slightly low of two fifths $(38.8 \%)$ of the studied sample had satisfactory level of behavior. Also, in this study there is no of the studied sample had good level of behavior toward safe household waste disposal.

The findings of current study are contradicting with the survey conducted by Naing (2009) which reported that $(51.2 \%)$ of the sample had satisfactory level of behavior, $(32.2 \%)$ of the studied sample had poor level of behavior and $(16.5 \%)$ of the sample had good level of behavior. Our findings are inconsistence with the result of study carried out by Water Sanitation and Hygiene-Alek base (2012) found that $(20 \%)$ of the participants had good level of behaviors and $(80 \%)$ had poor level of behaviors. In the present study, diarrhea is the most common disease caused by waste with $(67.3 \%)$, followed by eye diseases with $(66.8 \%)$, skin diseases with $(52.6 \%)$, parasitic diseases with $(48.8 \%)$, dysentery with $(31.9 \%)$, typhoid fever with $(28.8 \%)$, scorpion bites with $(23.9 \%)$, poisoning from polluted foods or drinks with $(22 \%)$, HAV with $(17.2 \%)$ and snakes bites with $(3.2 \%)$.

In the current study there were relation between the disease caused by waste and socio-economic status of the family found that there was a statistical significant difference at $\mathrm{p}<0.05$ with all diseases except diarrhea and when makes relationship between diseases caused waste and knowledge of studied sample about safe household wastes disposal found that there was a statistical significant difference with all diseases except diarrhea and eye diseases. Another relation between diseases caused by wastes and behaviors about household wastes disposal found that there is a statistical significant difference with all diseases mentioned before except diarrhea, eye diseases and poisoning from polluted food or drink.

In the current study, found that relations between diseases caused by wastes and caring with animals and bird in the house found that there was a statistical significant difference with all mentioned diseases except eye diseases and poisoning from polluted food or drink.

The findings of the present study are contradicting

with study carried out by Ladu et al (2012) about solid waste disposal and its environmental impacts on human health in Juba town - south Sudan found that about $(26 \%)$ of sample suffer from diarrhea, $(18 \%)$ of participant suffer from HAV, (14\%) of sample size suffer from eye diseases, (10\%) of participant suffer from skin diseases and about (8\%) of sample size suffer from typhoid fever.

\section{Conclusion}

According to the findings and research question it was found that, There are relations between sex and knowledge about household wastes and there were relation between improper disposal of household wastes and diseases caused by wastes and also, found a statistical significant differences between diseases 
caused by wastes and caring with animals and birds in the house.

\section{Recommendation}

Health education program to the public about: solid waste and its related issues through mass media.

Animals and bird's pen should be separated from human living place and should be hygienic.

$\checkmark$ Plan, implement and evaluate strict rules regarding sweeping of houses and streets, sanitary collection and disposal of community wastes that have to be obeyed by villagers.

$\square$ More research should be carrying out about how the Egyptian community can benefit from household wastes.

\section{Reference}

1. Abd El-Tawab. (2004): Socio economic scale, Faculty of Education, Assiut University.

2. Abul, S., (2010): Environmental \& health impact of solid waste disposal at management dumpsite in Manzini: Swaziland. Journal of sustainable development in Africa 12(7) p.70.

3. Allender, J., Rector, C., \& Warner, K., (2010): Public Health Essentials for Community Health Nursing, Community Health Nursing, Promoting and protecting the publics Health. Philadelphia. Chapter(9), $7^{\text {th }}$ ed New York, p.261.

4. Fischer, C., \& Crowe, M., (2000): Household $\&$ municipal waste. Comparability of Data in European Environment Agency member countries. Copenhagen: European Environment Agency. Envi. Health.(6)2. pp. 143-150.

5. Keller, L., Strohschein, S., Lia-Hoagberg, B., \& Schaffer, M., (2004): Population- based public health intervention: practice based and evidence supported. public health nursing. 21(5): pp. 453-468.

6. Ladu, J., Osman, M., \& Lu, X., (2012): Solid waste management \& its environmental impacts on human health in Juba town - south Sudan. Scholarly Journals of Biotechnology, 1(2): p. 3435.

7. Longe, O., Longe, E., \& Ukpebor, E., (2009): People's Perception on Household Solid Waste Management in Ojo Local Government Area in Nigeria. Iran. J. Environ. Health sci. Eng. 6 (3): pp. 212-14.

8. Miller, G., (2002): Living in the Environment. principles, connection \& solution wads worth Group Brook/ Cole, 2nd Edition. Philadelphia. p.4-7.

9. Moghadam, M., and Ehrampoush, M., (2005): Survey of knowledge, attitude \& practice of Yazd university of medical sciences student about solid wastes disposal \& recycling. Iranian J Env Health Sci Eng, vol (2) No (2), pp. 26-30.

10. Naing, Y., (2009): Factors influencing the practice of household waste management among Myanmar migrant in muang district, Ranong province, Thailand. p.4-5, 73-7.

11. Nies, M., \& McEwen, M., (2012): Factors that influence the Health of the Community Community /Public Health Nursing, Promoting the Health of Population, chap(3), $5^{\text {th }}$ ed, New York. Pp. 248-50, 1455-1457.

12. Smith, C., and Maurer, F., (2000): Community Health Nursing Theory \& Practice, Environmental Issues: At Home, at Work and in the Community, chapter $(24), 4^{\text {th }}$ ed, London. P.665.

13. Water Sanitation \& Hygiene-Alek base (2012): Knowledge, attitude \& practice survey report Gogrial west county, Warrap state. South Sudan, solid waste management. p.10. 